\title{
The antitumor effect of a novel differentiation inducer, 2, 2-Bis (4-(4-amino-3-hydroxyphenoxy) phenyl) adamantane (DPA), in combinatory therapy on human colon cancer
}

\author{
JANE-JEN WANG ${ }^{1}$, JEN-YI LEE ${ }^{2}$, YU-CHEN CHEN ${ }^{2}$, YAW-TERNG CHERN $^{3}$ and CHIN-WEN CHI ${ }^{2,4}$ \\ ${ }^{1}$ National Taipei College of Nursing; ${ }^{2}$ Institute of Pharmacology, School of Medicine, National Yang-Ming University, \\ Taipei 112; ${ }^{3}$ Department of Chemical Engineering, National Taiwan University of Science and Technology, Taipei 106; \\ ${ }^{4}$ Department of Medical Research and Education, Taipei Veterans General Hospital, Taipei 112, Taiwan
}

Received October 31, 2005; Accepted December 21, 2005

\begin{abstract}
An adamantane derivative, 2, 2-Bis (4-(4-amino-3hydroxyphenoxy) phenyl) adamantane (DPA), was found to inhibit the growth of several cancer cell lines in the National Cancer Institute (NCI) Anticancer Drug Screen system. Our previous study showed that DPA inhibited the growth of human colon cancer cell Colo 205 xenografts. DPAtreated cells were arrested at $\mathrm{G}_{0} / \mathrm{G}_{1}$, and the DPA-induced cell growth inhibition was irreversible after removal of DPA. Moreover, no acute toxicity was observed after an intraperitoneal challenge of DPA in nude mice weekly. In this study, we examined the in vivo therapeutic potential of DPA combined with clinical chemotherapeutic agent CPT-11 in Colo 205 cell xenografts. The in vitro cytostatic and differentiative effects of DPA on human colon cancer cells was also evaluated. DPA exerted growth inhibitory activities in vitro against three human colon cancer cell lines (Colo 205, HT-29, and HCT-15). DPA-treated cells showed a more adhesive epithelial phenotype. The differentiation markers of carcinoembryonic antigen (CEA) and fibronectin (FN) were significantly increased in colon cancer cells after treatment with DPA. Further studies showed the induction of p21/Cip1,
\end{abstract}

Correspondence to: Dr Chin-Wen Chi, Department of Medical Research and Education, Taipei Veterans General Hospital, No. 201, Section 2, Shih-Pai Road, Taipei 11217, Taiwan

E-mail: cwchi@vghtpe.gov.tw

Abbreviations: AMI, N-1-adamantylmaleimide; ATRA, all-trans retinoic acid; CDK, cyclin-dependent kinase; CEA, carcinoembryonic antigen; DMAMI, dimethyladamantylmaleimide; DMI, N-1diamantylmaleimide; DPA, 2,2-Bis (4-(4-amino-3-hydroxyphenoxy) phenyl) adamantine; DPD, 1, 6-Bis[4-(4-amino-3-hydroxyphenoxy) phenyl] diamantine; FN, fibronectin; $\mathrm{NaB}$, sodium butyrate; NCI, National Cancer Institute; NSCLC, non-small cell lung cancer; SCID, severe combined immune-deficiency

Key words: adamantane derivative, CPT-11, colon cancer, cytostatic, differentiation, p21/Cip1, p27/Kip1, E-cadherin
p27/Kip1, E-cadherin and dephosphorylated p120ctn expression was involved in DPA-induced anticancer effects. Interestingly, DPA-induced elevation of p21/Cip1 was independent of the induction of p53 in Colo 205 cells. In vivo results demonstrated that DPA enhanced the in vivo anticancer activity of the chemotherapeutic agent, CPT-11, by elevation of p53independent $\mathrm{p} 21 / \mathrm{Cip} 1$ and $\mathrm{p} 27 / \mathrm{Kip} 1$ expression. Our results suggest that DPA appears to be a new potentially less toxic modality of cancer combinatory therapy.

\section{Introduction}

Adamantane derivatives possess several attractive pharmacological activities, such as antibacterial, antifungal, antiviral and anticancer effects (1-3). Our previous study found that $\mathrm{N}$-1-adamantylcitraconimide, N-1-adamantylmaleimide (AMI) and N-1-diamantylmaleimide (DMI) exhibited modest growth-inhibitory activity against four cancer cell lines (Colo 205, HepG2, SK-BR-3 and Molt-4) (2). We also found that AMI was effective in inhibiting the growth of human gastric cancer cells both in vitro and in vivo and induced apoptosis in vitro (3). The AMI derivative dimethyladamantylmaleimide (DMAMI) induces apoptosis and inhibits the growth of human colon cancer Colo 205 in SCID mice (4).

In a recent study, we characterized the anticancer activities of diamantane derivatives using 60 human cancer cell lines in NCI Anticancer Drug Screen, and evaluated the structureactivity relationship. 1, 6-Bis [4-(4-amino-3-hydroxyphenoxy) phenyl] diamantane (DPD) exhibited marked anticancer activity on the sub-panel of 60 human cancer cell lines (5). The antiproliferative effects and differentiation-inducing property of DPD were demonstrated in human colon cancer cells, and the DPD-induced effects were irreversible after removal of DPD (6). DPD also induced apoptosis in human leukemic cells by elevation of reactive oxygen species (5). No acute toxicity was observed after an intra-peritoneal challenge of DPD in mice twice a week. For comparison between the anticancer activity of diamantane and adamantane derivatives, we further synthesized the new adamantane derivative, 2, 2-Bis (4-(4amino-3-hydroxyphenoxy) phenyl) adamantane (DPA), an analogue of DPD. In another recent study of ours, DPA also exhibited marked anticancer activities on the sub-panel of 60 
human cancer cell lines, especially colon cancer cell lines, and induced $\mathrm{G}_{1}$ arrest in Colo 205 and HT-29 cells (7).

Colon cancer is a major cause of mortality in the Western world (8). Although chemotherapy and radiation therapy have been attempted in adjuvant and palliative treatments, a more effective adjuvant therapy is needed for colon cancer patients. Nearly half of all patients with colon cancer still die of metastatic disease after curative surgery. New chemotherapeutic agents, such as topoisomerase I inhibitor irinotecan (CPT-11), are now used as a second-line chemotherapeutic agent for patients who have failed to respond to previous 5-FU-based chemotherapy, but the survival remains poor for patients with metastatic colorectal carcinoma $(9,10)$. Although CPT-11 has been shown to be highly effective in treatment of colon cancer, the dosage is limited by toxicities such as diarrhea (11). Therefore, developing new therapeutic drugs for colon cancer is a worthwhile task.

Disordered proliferation is one of the characteristics of malignant tumors. Multiple genetic alterations in tumor cells affect the regulation of the cell-cycle machinery $(12,13)$. The progression of cells through the cell cycle is under positive control by a series of specific cyclin/CDK (cyclin-dependent kinase) complexes and is negatively controlled by specific CDKI (CDK inhibitors) $(14,15)$. A number of proteins (p15, p16, p21/Cip1, and p27/Kip1) have been described to have inhibitory activity against the CDK complexes $(16,17)$. The activity of the CDK family appears to be increased in some tumor cells in which these natural inhibitors of CDK activity may be absent or mutated $(18,19)$. Thus, the development of potent CDK inhibitors would represent a novel approach for the inhibition of tumor cell growth.

The use of chemical agents to induce differentiation of tumor cells has received widespread attention as a potentially less toxic cancer therapy. Human colon cancer cells exhibit different degrees of histological differentiation. The morphology of HT-29 cells can be modulated to express distinct differentiation markers following treatment with various inducers $(20,21)$. The induction of differentiation in human colon cancer cells is associated with an upregulation of the differentiation-related molecules, fibronectin (FN) and carcinoembryonic antigen (CEA) (22-24). Differentiation inducers, such as retinoic acid (RA) and sodium butyrate $(\mathrm{NaB})$, increase the differentiated phenotype of several cell lines mediated by modulations of cell adhesion molecules, including integrins, cadherins, and gelactin and, as a result, also inhibit cell proliferation (25-27).

Regulation of cell-cell and cell-extracellular matrix (ECM) interaction is important for development, regeneration, tumor progression and, particularly, invasion and metastasis $(28,29)$. The E-cadherin-catenin adhesion complex is one of the main events in the early and late steps of cancer development (30). In general, E-cadherin and catenin staining is strong in welldifferentiated cancers that maintain their cell adhesiveness and are less invasive, but is reduced in poorly differentiated tumors (30). It has become clear that E-cadherin is involved in contact inhibition of cell growth by inducing cell-cycle arrest $(31,32)$. The human colon adenocarcinoma cell line, Colo 205, has lost adhesive capacity to the extracellular matrix (ECM) and shows a round and floating cell shape (33). Colo 205 cells show defective cell adhesion possibly owing to aberrant p120ctn phosphorylation (34). However, in v-Src-transfected L-cells, tyrosine phosphorylation of p120ctn was dependent on its association with E-cadherin and resulted in reduced cell adhesion (35).

In this study, we evaluated the in vitro effects of DPA on proliferation and induction of differentiation of colon cancer cells, and the in vivo therapeutic potential of DPA in combination with CPT-11. The expression of negative cell-cycle regulators and adhesion molecules in DPA-treated colon cancer cells were examined. Results from this study demonstrated that DPA enhanced the in vivo anticancer activity of the chemotherapeutic agent, CPT-11, by elevation of the expression of $\mathrm{p} 21 / \mathrm{Cip} 1$ and $\mathrm{p} 27 / \mathrm{Kip} 1$. In addition, the DPA-induced differentiation in colon cancer cells was associated with an increased production of CEA and FN, and DPA-treated cells showed a more adhesive epithelial phenotype. The expression of p21/Cip1, p27/Kip1, E-cadherin, $\beta$-catenin and p120 was involved in DPA-induced in vitro cytostatic and differentiation effects.

\section{Materials and methods}

Cell culture and DPA treatment. Three colon cancer cell lines, Colo 205 (ATCC: CCL-222), HT-29 (ATCC: HTB-38), and HCT-15 (ATCC: CCL-225), were used in this study. Colo 205 cells were cultured in RPMI-1640 with $10 \%$ fetal bovine serum (Hyclone, Logan, UT). HT-29 cells were cultured in McCoys 5A with $10 \%$ fetal bovine serum and $0.01 \mathrm{mg} / \mathrm{ml}$ gentamycin (Gibco, Grand Island, NY). HCT-15 cells were cultured in RPMI-1640 with $10 \%$ fetal bovine serum and $0.01 \mathrm{mg} / \mathrm{ml}$ gentamycin. Cells were incubated in a humidified atmosphere of $5 \% \mathrm{CO}_{2}$ in air at $37^{\circ} \mathrm{C}$. DPA was dissolved in DMSO at a stock concentration of $10 \mathrm{mM}$ and added to culture media at a final concentration of $1-8 \mu \mathrm{M}$. The final concentration of DMSO was $0.1 \%$. Cells were seeded at $5 \times 10^{5}$ cells $/ 25 \mathrm{~T}$ or $1 \times 10^{6}$ cells $/ 75 \mathrm{~T}$ flask in growth medium. On the following day, the cells were replenished with medium containing DPA. Cells were harvested and counted by haemocytometer at 24, 48 and $72 \mathrm{~h}$ after treatment with DPA and used for further analysis.

Reagents. Antibodies against p21/Cip1 and p27/Kip1 were from BD Transduction Laboratories (Lexington, KY). Antibodies against p53 and p120 were from Santa Cruz Biotechnology (Santa Cruz, CA). Enhanced chemiluminescence reagents were obtained from Amersham Pharmacia Biotech (Buckinghamshire, UK) and the protein assay reagents were from Bio-Rad (Hercules, CA).

Assessment of cell viability. At appropriate times after DPA exposure, attached cells were trypsinized and combined with non-adherent cells. After centrifugation, cells were resuspended in culture media and stained with $0.4 \%$ trypan blue, and viable cells were counted using a haemocytometer.

DNA staining. A Cycle Test ${ }^{\mathrm{TM}}$ Plus DNA reagent kit (BectonDickinson, San Jose, CA) was used for DNA staining. After washing the cells twice with buffer solution, the cell concentration was adjusted to $1 \times 10^{6} / \mathrm{ml}$, and $0.5 \mathrm{ml}$ of the cell suspension was centrifuged at $400 \mathrm{x} \mathrm{g}$ for $5 \mathrm{~min}$ at room 
temperature $\left(20-25^{\circ} \mathrm{C}\right)$. The cell pellet was added to $250 \mu 1$ of Solution A (trypsin buffer) and gently mixed. After incubation at room temperature for $10 \mathrm{~min}, 200 \mu 1$ of Solution B (trypsin inhibitor and RNase buffer) was added to each tube, gently mixed and then incubated at room temperature for $10 \mathrm{~min}$. This was followed by the addition of $200 \mu 1$ of Solution C (propidium iodide stain solution) and incubated for $10 \mathrm{~min}$ in the dark on ice $\left(2-8^{\circ} \mathrm{C}\right)$. The sample was filtered through a 50 -mm nylon mesh and used for flow cytometric analysis.

Flow cytometry. Cells $(10,000-20,000)$ were analyzed on a flow cytometer (FACScalibur; Becton-Dickinson, USA) using an argon-ion laser $(15 \mathrm{~mW})$ with the incident beam at $488 \mathrm{~nm}$. The red fluorescence (FL-2) was collected through a $585-\mathrm{nm}$ filter and the green fluorescence (FL-1) was collected through a 530-nm filter. The cell-cycle data was analyzed by ModFit and Cellquest softwares.

FN and CEA production. Cells ( $1 \times 10^{6}$ per dish) were seeded on $10-\mathrm{cm}$ dishes and allowed to attach overnight and then the medium was discarded and replenished with medium containing DPA for incubation at $37^{\circ} \mathrm{C}$ for $72 \mathrm{~h}$. The conditioned medium was collected and stored at $-20^{\circ} \mathrm{C}$ before analysis. Levels of FN production were measured by a quantitative enzyme-linked immunosorbent assay (ELISA, Chemicon; USA), using primary rabbit anti-human FN antibody and goat anti-rabbit peroxidase conjugated secondary antibody. Levels of CEA production were measured by a radioimmunoassay (RIA) kit (CIS Bio International; France). Both FN and CEA concentrations were normalized to nanograms per $1 \times 10^{6}$ cells. The results are expressed as fold of increase of duplicate assays from one of two independent experiments.

Cellular morphology. Cells ( $1 \times 10^{6}$ per dish) were seeded into $10-\mathrm{cm}$ dishes and allowed to attach overnight. The culture medium was replenished with medium containing the DPA, and then incubated at $37^{\circ} \mathrm{C}$ for $72 \mathrm{~h}$ in a humidified incubator. At the end of the $72 \mathrm{~h}$, the ability of DPA to induce morphological changes in the Colo 205 cells was evaluated by phase contrast microscopy.

E-cadherin staining. The DPA-treated cells were washed with wash buffer, and fixed in $4 \%$ paraformaldehyde in PBS for $15 \mathrm{~min}$. Cells were then washed with PBS. Cold $0.2 \%$ Triton X-100 $5 \mathrm{ml}$ in wash buffer was added to the cells and incubated for $5 \mathrm{~min}$. After $1 \%$ bovine serum albumin blocking for $30 \mathrm{~min}$, the cells were incubated with $20 \mu \mathrm{l}$ of the FITCconjugated mouse anti-human E-cadherin monoclonal antibody (BD Pharmingen) or isotype control antibody (mouse $\mathrm{IgG}_{1}$, clone MOPC-21) for another $30 \mathrm{~min}$ at room temperature in the dark. The cells were washed with wash buffer, and used for fluorescence microscope analysis.

Western blotting. The treated-cells were washed twice with ice-cold phosphate-buffered saline (PBS) and lysed in a lysis buffer (50 mmol/l Tris-HCl, pH 8.0, 150 mmol/ $1 \mathrm{NaCl}, 0.5 \%$ Nonidet P-40, $1 \mathrm{mmol} / \mathrm{l}$ ethylenediaminetetraacetic acid, $\mathrm{pH} 8.0,1 \mathrm{mmol} / 1$ ethylene glycol-bis (ß-aminoethylether)$\mathrm{N}, \mathrm{N}$-tetraacetic acid, $\mathrm{pH} 8.0,1 \mathrm{mmol} / 1$ sodium fluoride, $0.1 \mathrm{mmol} / 1$ sodium orthovanadate, $1 \mathrm{mmol} / 1$ dithiothreitol,
$200 \mu \mathrm{g} / \mathrm{ml}$ phenylmethylsulfonyl fluoride, $2 \mu \mathrm{g} / \mathrm{ml}$ aprotinin, and $2 \mu \mathrm{g} / \mathrm{ml}$ leupeptin). Cell lysates were centrifuged at $12,000 \mathrm{~g}$ for $30 \mathrm{~min}$ at $4^{\circ} \mathrm{C}$, and supernatants were separated. Protein concentration was measured using a Bio-Rad protein assay kit. After boiling for $5 \mathrm{~min}$ in the presence of 2-mercaptoethanol, samples containing cell lysate protein were separated on $10 \%$ or $7.5 \%$ sodium dodecyl sulfate (SDS)-polyacrylamide gel and then transferred onto equilibrated polyvinylidene difluoride membranes (Bio-Rad). After skimmed-milk blocking, the membranes were incubated with the primary antibodies described above. The bound antibodies were detected with horseradish peroxidase-labeled sheep anti-mouse IgG using an enhanced chemiluminescence detection system (ECL kit, Amersham Pharmacia Biotech).

$R T$-PCR analysis of E-cadherin and $\beta$-catenin $m R N A$ expression. The expression of E-cadherin and $B$-catenin mRNA was measured by RT-PCR. RNA $(1 \mu \mathrm{g})$ isolated from control or DPA-treated cells was first converted to cDNA by reverse transcription using M-MLV reverse transcriptase (Invitrogen, US) and the Homo-Oligomeric DNA pd(T) ${ }_{12-18}$ (Amersham, UK). The cDNA was then amplified by PCR. The E-cadherin and $B$-catenin primers were as follows: forward, 5'-AGGCCAAGCAGCAGTACATT; backward, 5'ATTCACATCCAGCACATCCA; and forward, 5'-TTGAAA ATCCAGCGTGGACA; backward, 5'-TCGAGTCATTGCA TACTGTC, respectively. The reaction was run at $94^{\circ} \mathrm{C}(1 \mathrm{~min})$, $60^{\circ} \mathrm{C}(1 \mathrm{~min})$, and $72^{\circ} \mathrm{C}(1 \mathrm{~min})$ for 20 cycles, which was within the linear reaction window. GAPDH was also measured by RT-PCR from the same RNA samples and used as an internal control. The GAPDH primers were: forward, 5'-CCA TCAATGACCCCTTCATTGACC; backward, 5'-GAAGGC CATGCCAGTGAGCTTCC.

Enhancement of the in vivo antitumoral activity of chemotherapeutic agent CPT-11 by DPA in the ICR-nu nude mice tumor xenograft model. All in vivo experiments were carried out with ethics committee approval and met the standards required by the UKCCCR guidelines (36). Eightweek-old male ICR-nude mice were obtained from the National Laboratory Animal Center of National Applied Research Laboratories, Taipei, Taiwan and housed in a laminar flow room under sterilized conditions with temperature maintained at $25^{\circ} \mathrm{C}$ and light controlled at a 12-h light and 12-h dark cycle. Colo 205 cells were harvested and resuspended in serum-free RPMI-1640 medium. Cells were adjusted to $1 \times 10^{7}$ cells $/ \mathrm{ml}$, and inoculated $0.1 \mathrm{ml}$ into nude mice. Each experimental group included 7-8 mice bearing tumors. DPA and CPT-11 were dissolved in DMSO and normal saline, respectively. Treatment started when tumor size was 3-5 mm. DPA $(20 \mathrm{mg} / \mathrm{kg})$, CPT-11 $(15 \mathrm{mg} / \mathrm{kg})$ or a combination of DPA and CPT-11 were administered via i.p. injection twice a week (volume of injection: $0.1 \mathrm{ml} / 20 \mathrm{~g}$ of body weight). The control group received $0.1 \mathrm{ml}$ DMSO vehicle. Tumor size and body weight were monitored twice a week throughout the experiment. The tumor size (V) was measured using a vernier caliper twice a week and was calculated according to the following formula: $\mathrm{V}\left(\mathrm{mm}^{3}\right)=0.4 \mathrm{AB}^{2}$, where A and $\mathrm{B}$ are the longest and shortest diameter, respectively (37). At day 24, all mice were sacrificed by $\mathrm{CO}_{2}$ gas. Tumors, livers, kidneys, 


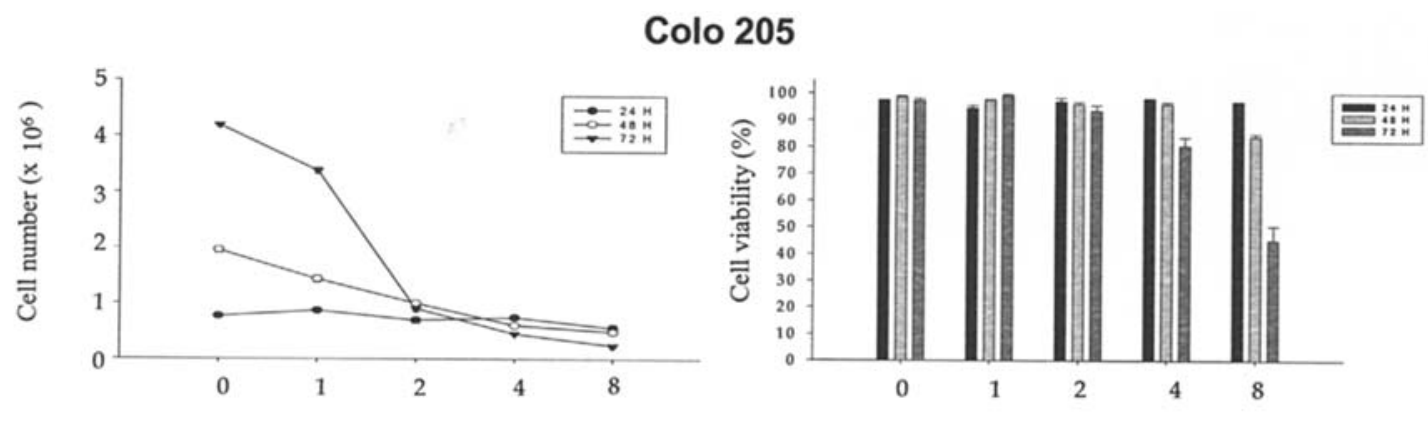

HT-29
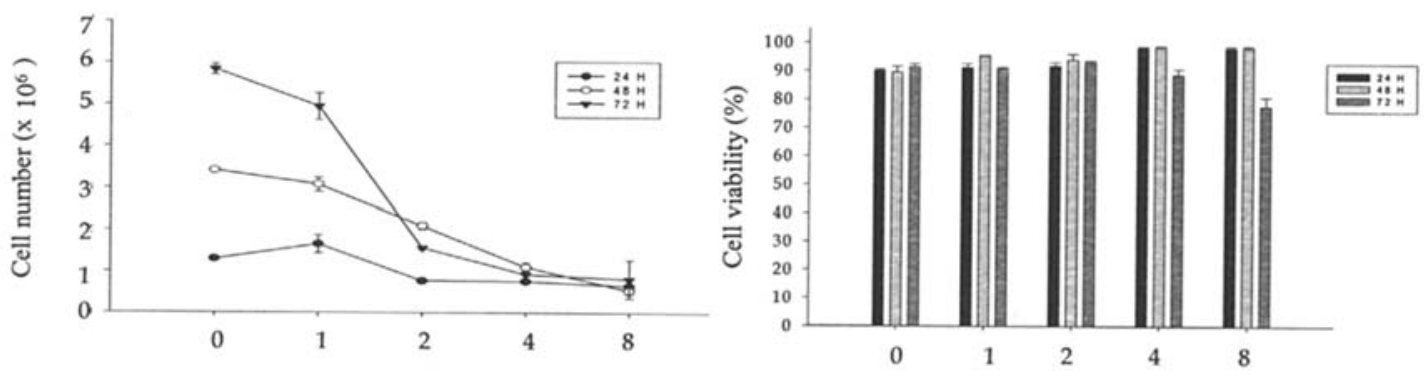

HCT-15
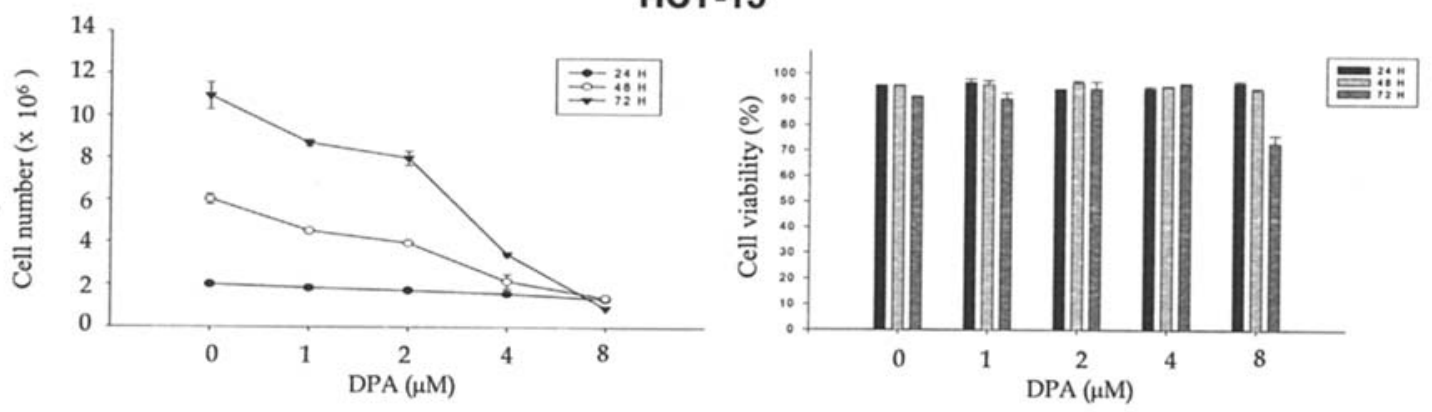

Figure 1. The effect of DPA on the growth of three human colon cancer cell lines. Cells were seeded at $5 \times 10^{5}$ cells $/ 60 \mathrm{~mm}$ or $1 \times 10^{6}$ cells $/ 100$-mm dish in growth medium. On the following day, the cells were replenished with medium containing 1, 2, 4 or $8 \mu \mathrm{M}$ DPA. Cells were harvested and counted by hemocytometer. Each point represents the mean \pm standard error of duplicate cultures from one of three independent experiments.

and lungs were collected, fixed, embedded and stained with hematoxylin and eosin for pathological analysis.

Statistical analyses. All data are expressed as mean \pm standard error. Difference between groups was assessed using Student's t-test. $\mathrm{p}<0.05$ was considered as a significant difference.

\section{Results}

Antiproliferative effects of DPA. To determine the ability of DPA to inhibit cell proliferation in three colon cancer cell lines, cells were incubated in the absence or presence of increasing concentrations of DPA for 24-72 h. As shown in Fig. 1, we observed an inhibition of cell growth in DPA-treated cells as compared with vehicle controls. Significant growth inhibition was observed at 48 and $72 \mathrm{~h}$ in Colo 205 cells and HT-29 cells after treatment with 2, 4 and $8 \mu \mathrm{M}$ DPA, respectively. In the relatively resistant cell line, HCT-15, growth inhibition was observed after treatment with 4 and $8 \mu \mathrm{M}$ DPA at 48 and $72 \mathrm{~h}$.

The expression level of p21/Cip1,p27/Kipl and p53 in DPAtreated cells. Previous studies have demonstrated DPA-induced

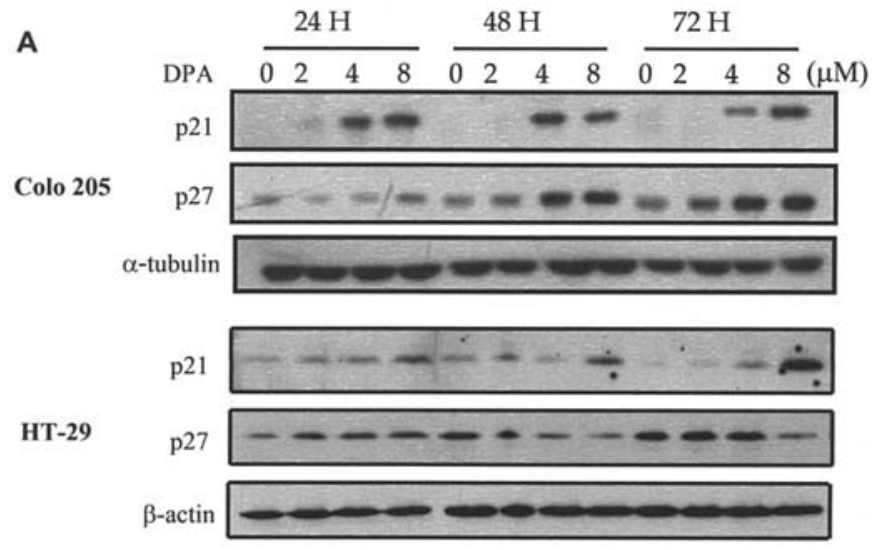

B

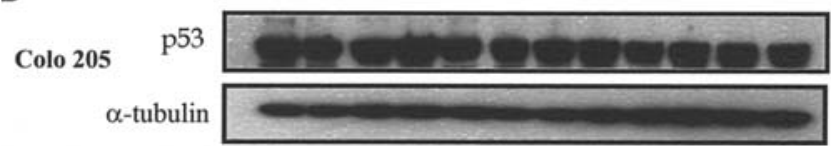

Figure 2. (A) Immunoblot analysis of p21/Cip1, p27/Kip1 in DPA-treated cells; and (B) p53 in DPA-treated Colo 205 cells. Cells $\left(5 \times 10^{5} / 10-\mathrm{cm}\right.$ dish) were cultured without or with 2, 4 and $8 \mu \mathrm{M}$ DPA for 24-72 $\mathrm{h}$. The cellular proteins were analyzed by SDS-polyacrylamide gel electrophoresis and transferred to the PVDF membrane, followed by immunoblots with monoclonal antibodies for p21/Cip1, p27/Kip1 and p53. 
CEA

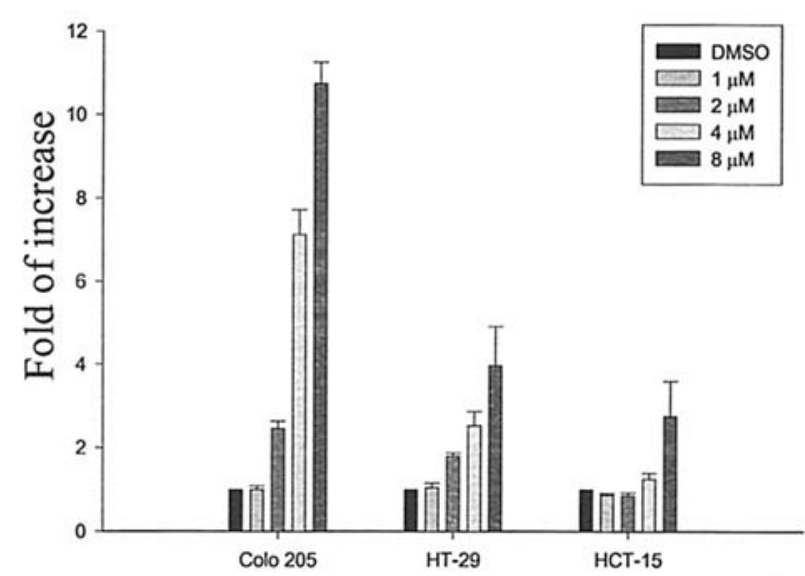

FN

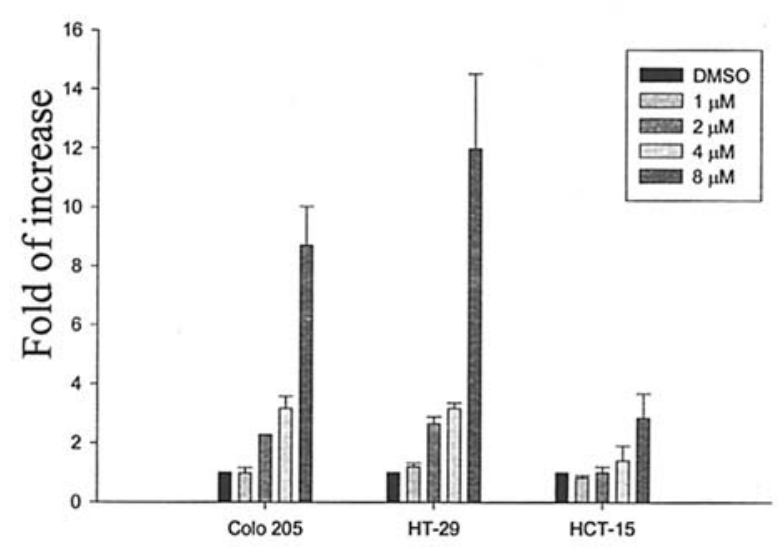

Figure 3. Induction of CEA and FN production by DPA. Conditioned medium from cells treated with 1, 2, 4 or $8 \mu \mathrm{M}$ DPA for $72 \mathrm{~h}$ was analyzed for CEA and FN production by ELISA. CEA and FN concentrations were normalized to $\mathrm{ng} / \mathrm{ml} / 1 \times 10^{6}$ cells. Data are shown as the fold of increase to DMSO control \pm standard error of the mean of duplicate assays from one of two independent experiments.

$\mathrm{G}_{0} / \mathrm{G}_{1}$ arrest in Colo 205 and HT-29 cells (5). Changes of $\mathrm{G}_{0} / \mathrm{G}_{1}$ regulatory protein levels in Colo 205 and HT-29 cells in response to DPA $(2-8 \mu \mathrm{M})$ treatment were then examined. p21/Cip1 is a key regulator of cell entry into mitosis. A major function of the $\mathrm{p} 27 / \mathrm{Kip} 1$ protein is to bind to the cyclin E/ CDK 2 complex and inhibit its kinase activity. Therefore, we examined whether the negative cell-cycle regulators, CDKIs p21/Cip1 and p27/Kip1, and the p21/Cip1 upstream protein p53 were involved in the DPA-induced- $G_{1}$ arrest effect (7), using Western blotting. Our results revealed that $\mathrm{p} 21 / \mathrm{Cip} 1$ expression was initially elevated in HT-29 and Colo 205 at $24 \mathrm{~h}$ and was persistent for at least $72 \mathrm{~h}$ after 4-8 $\mu \mathrm{M}$ DPA treatment (Fig. 2). p27/Kip1 expression was initially elevated in Colo 205 at $24 \mathrm{~h}$ and was persistent for at least $72 \mathrm{~h}$ after 4-8 $\mu \mathrm{M}$ DPA treatment. The inhibition of the level of $\mathrm{p} 27 /$ Kip1 was observed in HT-29 at 48-72 h after $8 \mu \mathrm{M}$ DPA treatment. The level of the $\mathrm{p} 21 / \mathrm{Cip} 1$ upstream regulators $\mathrm{p} 53$ was not changed in Colo 205 cells after 2-8 $\mu \mathrm{M}$ DPA treatment (Fig. 2).

The induction of CEA and FN expression. Fig. 3 illustrates the increased production of CEA and FN in Colo 205, HT-29 and HCT-15 cells after DPA treatment for $72 \mathrm{~h}$. DPA $(2-8 \mu \mathrm{M})$ treatment of these cells resulted in increased secretion of CEA and FN into the culture medium. An increase of 7.1- to 10.7and 3.6- to 8.7-fold in soluble CEA and FN, respectively, was seen in Colo 205 cells after treatment with 4-8 $\mu \mathrm{M}$ DPA as compared to the untreated control cells. The HT-29 cells also showed a 2.5- to 3.9- and 3.3- to 12.0-fold increase in CEA and FN production, respectively, after treatment with $4-8 \mu \mathrm{M}$ DPA. The HCT-15 cells showed less response to DPA treatment, a more than 2-fold increase in CEA and FN production was observed after treatment with $8 \mu \mathrm{M}$ DPA.

Effect of DPA on morphological change and E-cadherin localization in Colo 205 cells. To further investigate the DPA-induced morphological change in Colo 205 cells, the cells were treated with $4 \mu \mathrm{M}$ DPA for $48-72$ h. Fig. $4 \mathrm{~A}$ shows that the Colo 205 cells grew as dispersed cells and only lightly attached to the culture dish. After treatment with DPA for $72 \mathrm{~h}$, the cells clumped into larger aggregates. The DPA-induced compact aggregate formation in Colo 205 cells was irreversible after removal of DPA (data not shown). Fig. 4B shows the localization of E-cadherin in DPA-treated Colo 205 cells. The expression level of E-cadherin redistributed from the cytoplasm to cell membrane.

$R T$-PCR analysis of E-cadherin and $\beta$-catenin $m R N A$ expression. E-cadherin is bound via series of undercoat proteins, the catenins, to the actin cytoskeleton (38). This linkage between transmembranous cadherins and actin filaments of the cytoskeleton is necessary to form strong cell-cell adhesion (39). To assess whether the changes of E-cadherin and $B$ catenin were observed in DPA-treated cells, the expression of E-cadherin and B-catenin mRNA in DPA-treated cells were analyzed by RT-PCR. Fig. 5 shows that the expression of E-cadherin mRNA was increased, and B-catenin mRNA was slightly decreased in $4 \mu \mathrm{M}$ DPA-treated Colo 205 cells at 12-48 h. Thus, it appeared that the changes in expression of E-cadherin and $\beta$-catenin were associated with increased cellcell adhesion in DPA-treated cells.

The expression level of p120 in DPA treated cells. Colo 205 cells show defective cell adhesion, possibly owing to aberrant p120ctn phosphorylation $(34,40)$. p120ctn can regulate cell adhesion and motility through the actin cytoskeleton (40). To assess whether the changes of p120 were involved in DPAinduced Colo 205 cell aggregation, the expression of p120 in DPA-treated cells was analyzed by Western blotting. Fig. 6 shows that the expression of dephosphorylated p120 was increased in 4-8 $\mu \mathrm{M}$ DPA-treated Colo 205 cells at 48-72 h.

DPA enhanced the in vitro antitumoral activity of CPT-11. To evaluate whether DPA could enhance the antitumoral activity of the chemotherapeutic agent, CPT-11, the MTT assay was used. The population of sub- $\mathrm{G}_{0} / \mathrm{G}_{1}$ phase in Colo 205 cells 
A

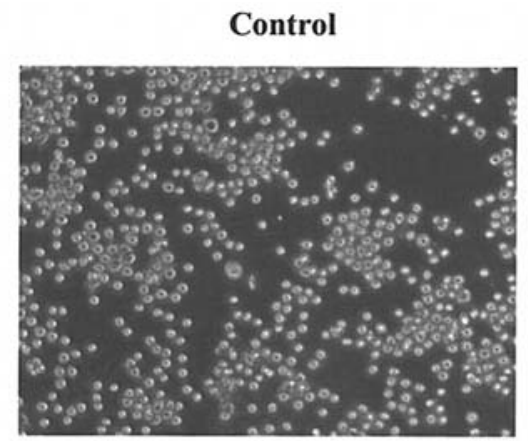

B
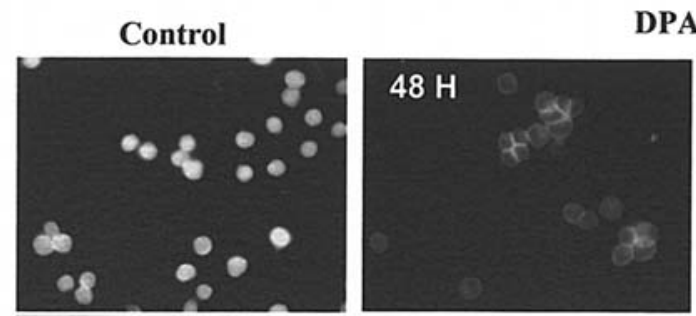

Figure 4. Effect of DPA on morphological change and E-cadherin localization in colon cancer cells. (A) The control cells have a rounded morphology; after treatment with $4 \mu \mathrm{M}$ DPA for $72 \mathrm{~h}$, an aggregation morphology appeared. Magnification, x200. (B) Localization of E-cadherin on the cell-surface of DPAtreated Colo 205 cells. Cells were cultured with or without $4 \mu \mathrm{M}$ DPA for 48 or $72 \mathrm{~h}$, fixed, and stained with anti-E-cadherin. Whereas E-cadherin appeared to be diffusely present on control cells, it is localized to cell-cell contact sites of DPA-induced adherent cells. Magnification, x600.

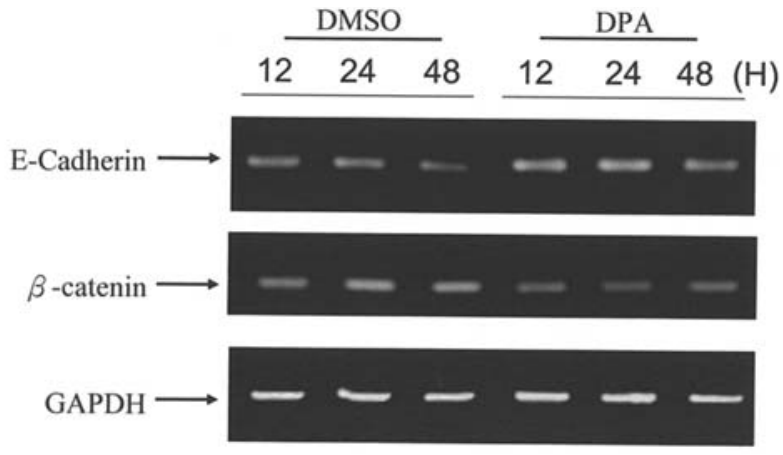

Figure 5. RT-PCR analysis of E-cadherin and ß-catenin mRNA in DPAtreated Colo 205 cells. Cells were treated with $4 \mu \mathrm{M}$ DPA for $12-48 \mathrm{~h}$. The RNA $(1 \mu \mathrm{g})$ isolated from the control or DPA-treated cells was analyzed by RT-PCR as described in Materials and methods. The representative Ecadherin and B-catenin mRNA expression in treated cells is from one of two reproducible experiments.

after treatment with DPA, CPT-11, or DPA in combination with CPT-11 was examined by flow cytometry. Fig. 7A shows that $2 \mu \mathrm{M}$ DPA combined with $25 \mu \mathrm{g} / \mathrm{ml} \mathrm{CPT}-11$ showed increased in vitro antitumoral activity as compared to that of DPA or CPT-11 alone. The population of apoptotic sub- $\mathrm{G}_{0} / \mathrm{G}_{1}$ Colo 205 cells in the combination of DPA and CPT-11 group was increased, as compared to DPA or CPT-11 alone (Fig. 7B).

DPA enhanced the in vivo antitumor effect of CPT-11 in human colon cancer xenografts. To further investigate whether DPA could enhance the in vivo antitumoral activity of the chemotherapeutic agent, CPT-11, Colo 205 cells were transplanted into ICR nude mice and, when the tumors were palpable (3-5 $\mathrm{mm})$, the mice were treated with vehicle control, DPA

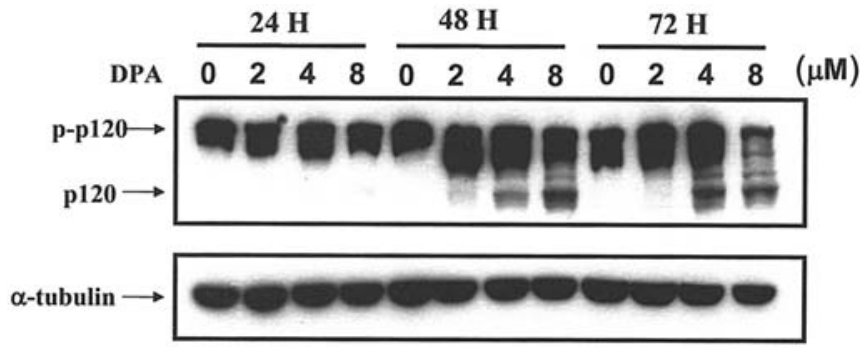

Figure 6. Immunoblot analysis of p120 in DPA-treated cells. Cells $\left(5 \times 10^{5 /}\right.$ 10-cm dish) were cultured with or without 2, 4 and $8 \mu \mathrm{M}$ DPA for 24-72 $\mathrm{h}$. The cellular proteins were analyzed by SDS-polyacrylamide gel electrophoresis and transferred to the PVDF membrane, followed by immunoblots with monoclonal antibodies for p120ctn and p-p120ctn.

(20 mg/kg, i.p., twice a week), CPT-11 (15 mg/kg, i.p., twice a week), or DPA in combination with CPT-11. Fig. 8A shows that the tumor size from control animals showed an average of $510.3 \mathrm{~mm}^{3}$ at the end of this study. In contrast, the tumor size from the DPA plus CPT-11 combination treatment group had an average of only $33.6 \mathrm{~mm}^{3}$. The tumor size of DPAand CPT-11-treated animals was 209.6 and $121.8 \mathrm{~mm}^{3}$, respectively. The antitumoral activity of DPA in combination with CPT-11 showed a 6- and 3-fold increase as compared to DPA and CPT-11 alone, respectively. These results clearly show that DPA enhanced the antitumoral activity of CPT-11.

The challenge of DPA $(20 \mathrm{mg} / \mathrm{kg}$, i.p., twice a week) or DPA in combination with CPT-11 in nude mice produced no obvious acute toxicity. No significant reduction in body weight was observed in DPA-treated mice (Fig. 8B). In addition, no tissue damage was observed in liver, lung or kidney after examination of the tissue slices stained with hematoxylin and eosin (data not shown). 
A

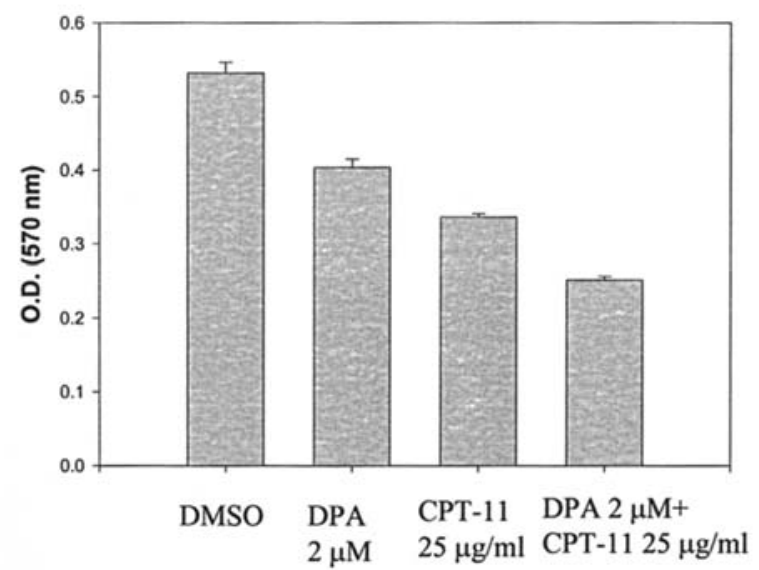

B

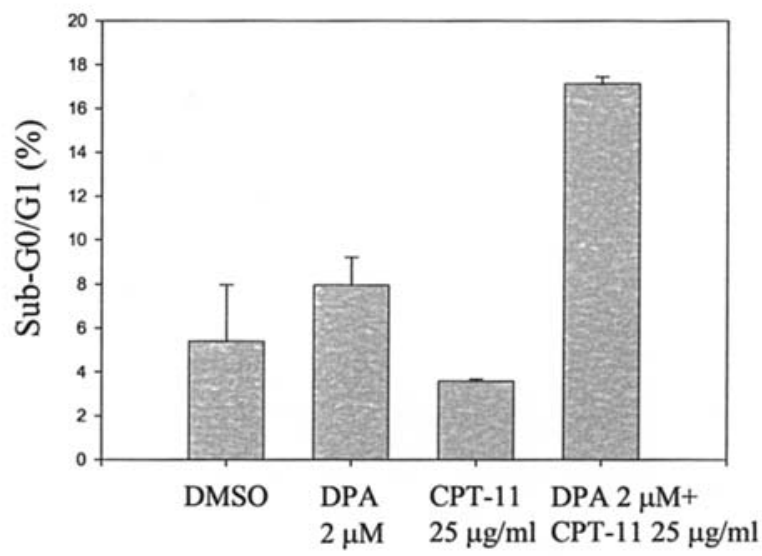

Figure 7. Enhancement of the in vitro antitumoral activity of CPT-11 by DPA. (A) The in vitro antiproliferaive effect of DPA or CPT-11 alone, or DPA combined with CPT-11 in Colo 205 cells was examined by MTT assay. (B) The population of sub-G $\mathrm{G}_{0} \mathrm{G}_{1}$ in DPA or CPT-11 alone, or DPA combined with CPT-11 cells, was examined by flow cytometry.

A

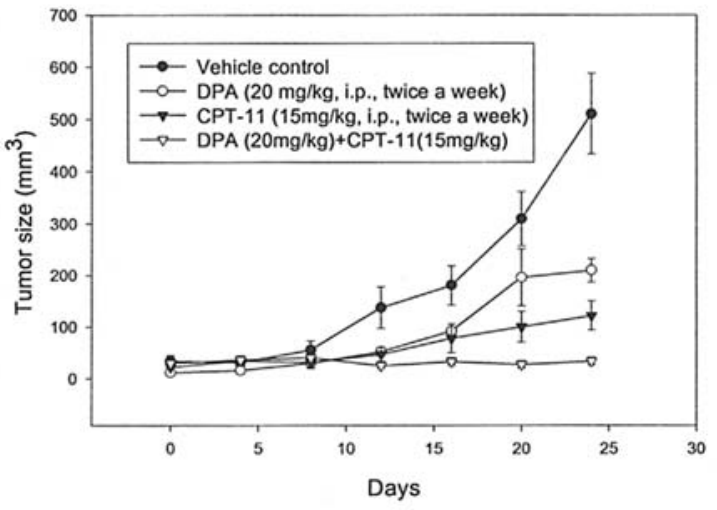

B

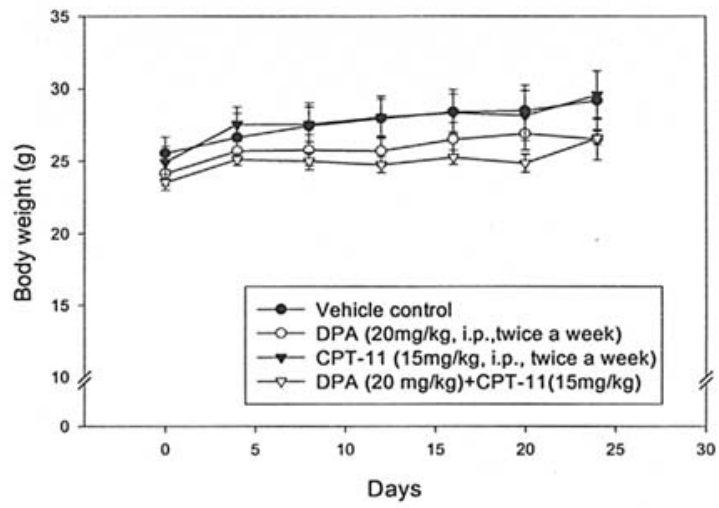

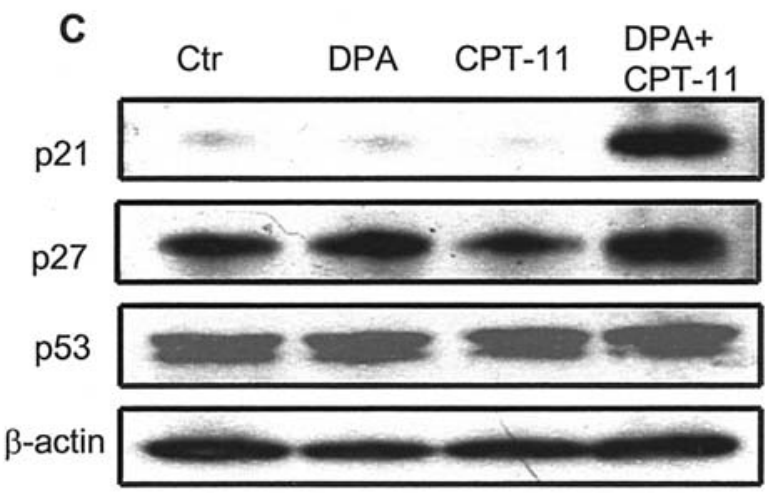

Figure 8. Enhancement of the antitumoral activity of CPT-11 by DPA. (A) The in vivo antiproliferative effect of DPA or CPT-11 alone, or DPA combined with CPT-11 for human colon cancer xenografts. DMSO served as control group. When the tumors were palpable (3-5 mm), the ICR nude mice were either treated with vehicle control or DPA (i.p., twice a week). Data are the mean \pm standard error from 6 to 10 samples of one representative experiment. Treatment of nude mice with DPA (20 mg/kg) combined with CPT-11, the tumor growth was significantly $(\mathrm{P}<0.05)$ decreased in mice as compared to DPA or CPT-11 alone at the end of the experiment. (B) Changes in body weight of nude mice after treatment or non-treatment with DPA, CPT-11 or DPA combined with CPT-11. Each data point is the mean \pm standard error from 6 to 10 samples of one representative experiment. (C) The DPA-enhanced in vivo anticancer activity of the chemotherapeutic agent, CPT-11, is related to elevation of the expression of p21/Cip1 and p27/Kip1, but not p53.

The DPA-enhanced in vivo antitumor effect of CPT-11 is related to the elevation of the expression of $\mathrm{p} 21 / \mathrm{Cip} 1$ and p27/Kip1, but not p53. To further investigate the molecular mechanism of in vivo antitumor activity, the protein lysates from tumor tissue were used for Western blot analysis of p21/Cip1, p27/Kip1 and p53. Fig. 8C shows that the levels of p21/Cip1 and p27/Kip1 were increased in the tumor tissue of nude mice after co-treatment with DPA and CPT-11. However, 
the expression of p53 showed no change in these tumors. Results from this study showed that DPA enhanced the in vivo anticancer activity of CPT-11 by elevation of p21/Cip1 and p27/Kip1 through a p53-independent mechanism.

\section{Discussion}

In this study, we demonstrated that DPA is active in inhibiting the growth of human colon cancer cells. The combination of DPA with CPT-11 has significant synergistic effect against human colon cancer in vitro and in vivo. These observations provide significant information for consideration of DPA in clinical cancer chemotherapy.

In the current study, three colon cancer cell lines with distinct biological properties (i.e. morphological differentiation, CEA production, etc.) were used and treated with DPA. Colo 205 is a poorly differentiated cell line and HT-29 is a welldifferentiated cell line $(41,42)$. The two colon cancer cell lines regardless of their state of differentiation had their growth markedly slowed by DPA. The DPA-induced growth inhibition in Colo 205 and HT-29 cells was largely due to a $G_{1}$ arrest in cell-cycle progression (7). However, the multidrug-resistant HCT-15 (43) also showed response to DPA. Similar to DPDinduced antiproliferative effect (6), Colo 205 and HT-29 were more sensitive than HCT-15 to DPA-induced cell growth suppression.

The use of differentiation-inducing agents in human colon cancer has received widespread attention as a potentially less toxic cancer therapy. Differentiation-inducing agents often inhibit growth in conjunction with the induction of differentiation in cancer cells. Several studies have shown that the up-regulation of CEA and FN expression is associated with a differentiation induction response in human colon cancer cells (44-46). The differentiation-inducing agents, ATRA and $\mathrm{NaB}$, have been reported to enhance CEA and FN production in some colon cancer lines (47-49). DPA was a potent inducer of soluble CEA and FN production in the three colon cancer cell lines examined (Fig. 3), which produce CEA and FN constitutively. The Colo 205 and HT-29 cells, however, were relatively more responsive to DPA in CEA and FN production by comparison with HCT-15. DPA induced a strong increase in FN production in HT-29 cells, which was similar to ATRA (50). The ATRA-induced differentiation was also characterized by the morphological flattening of cells and tight junctions between adjacent cells in apical human colon cancer. In the present study, we observed that the morphology of DPA-treated cells increased their adherence to one another and changed their shape and properties to a more adhesive epithelial phenotype. The DPA-induced morphology changes are also similar to that of staurosporine induced effect in Colo 205 cells (34). However, no reversal in these morphological changes (data not shown) and growth inhibition was observed after removal of DPA in colon cancer cells (7). These results are also similar to the DPD-induced effect (6). The DPA-induced differentiation is in agreement with observations that $\mathrm{NaB}$ and ATRA induced differentiation in colon cancer cells $(47,50)$. Nevertheless, $\mathrm{NaB}$, at a millimolar dose, induced colon cancer cells to differentiate. However, the NaB-mediated HT29 differentiation was found to be reversible following a return to $\mathrm{NaB}$-free medium (51). In vivo, $\mathrm{NaB}$ has a half-life too short to produce any therapeutic effect. Our results show that DPA is more active than $\mathrm{NaB}$ in suppressing cell growth and concomitantly promoting differentiation of human colon cancer cells. These results suggest that the irreversible property of DPA can prolong the action half-life and provide a potentially less toxic therapy for human colon cancer.

The tumor suppressor has been implicated in a variety of cellular processes (52). Among the transcriptional targets of $\mathrm{p} 53$, the CDKI p21/Cip1 plays a key role in mediating $\mathrm{G}_{1}$ arrest (53). Another CDKI is p27/Kip1, which mediates growth arrest and is thought to play a critical role in negative regulation of cell division in vivo $(17,54)$. The outcome of CDKIs induction in most cells is cessation of cell proliferation, differentiation, or even cell death. In the present study we observed that the elevation of CDKIs p21/Cip1 and p27/Kip1 was p53 independent and involved in DPA-induced antiproliferative and differentiative activity in both Colo 205 cells (containing wild-type p53) and HT-29 cells (with mutated p53). This result together with our observation that DPA treatment did not result in any change in p53 expression (Fig. 2B) suggest that DPA-induced CDKI upregulation involves a p53-independent pathway.

It has been known that cell-cell adhesion is generally reduced in human cancers. Reduced cell-cell adhesiveness is associated with loss of contact inhibition of proliferation, thereby allowing escape from growth control signals (31). Alteration in the E-cadherin/catenin complex was observed in RA-treated human MCF-7 breast cancer cells (27). E-cadherin in colon cancer cells has been found to be decreased or with altered affinity (55). ß-catenin is thought to be involved in inhibiting apoptosis and promoting cellular proliferation and migration in colon cancer cells $(56,57)$. Our results show that treatment of colon carcinoma Colo 205 cells with DPA not only resulted in inhibition of cell proliferation but also increased cell adhesion. Immunofluorescence micrographs further demonstrated that the distribution of E-cadherin was altered and increased. E-cadherin level was observed at cellcell junctions in DPA-treated cells. This result agrees with our finding that the mRNA expression level of E-cadherin was increased in DPA-treated Colo 205 (Fig. 5). In contrast to E-cadherin, the mRNA expression of $\beta$-catenin was slightly decreased in DPA-treated Colo 205 cells.

Upregulation of tyrosine phosphorylation of $\beta$-catenin and p120ctn occurs frequently in surgical specimens of colorectal and lung cancer (30). Analysis of p120ctn isoforms in a variety of murine cell lines revealed that non-adherent cells do not express detectable levels of p120ctn (58). Colon carcinoma cells, Colo 205, show defective cell adhesion, possibly owing to aberrant p120ctn phosphorylation (34). p120ctn can regulate cell adhesion and motility through the actin cytoskeleton via Rho family GTPases (40). In this study, our observation of the decrease in the higher phosphorylation level of p120ctn in DPA-treated Colo 205 cells (Fig. 6) correlates well with increased cell adhesion.

Achieving pharmacologically effective doses of anticancer drugs without any toxicity is important. In this study, we observed that treatment of Colo 205 tumor-bearing nude mice with DPA or DPA in combination with CPT-11 significantly decreased the tumor size in mice as compared to control groups. Moreover, twice a week i.p. challenge of DPA or DPA in 
combination with CPT-11 in nude mice produced no obvious acute toxicity (Fig. 8). An important finding is that the cotreatment of DPA and CPT-11 increased a p53-independent induction of p21/Cip1 and p27/Kip1 in tumor tissue from nude mice. This result correlated well with our in vitro results of DPA-induced elevation of p21/Cip1 and p27/Kip1 in Colo 205 cells. These results suggest that p53-independent cell-cycle regulators, such as p21/Cip1 and p27/Kip1, and the cell adhesion molecules, E-cadherin, B-catenin and p120ctn, may be important targets of differentiation inducers. The potential of using a differentiation inducer such as DPA for combination therapy of colon cancer is worthy of further investigation.

\section{Acknowledgments}

We thank Dr A. F.-Y. Li for the pathological analysis. This study was supported by a grant from the National Science Council (NSC 93-2320-B-227-005), Taiwan.

\section{References}

1. Aigami K, Inamoto $\mathrm{Y}$, Takaishi $\mathrm{N}$ and Hattori K: Biologically active polycycloalkanes. 1. Antiviral adamantine derivatives. J Med Chem 18: 713-721, 1975

2. Wang JJ, Wang SS, Lee CF, Chung MA and Chern YT: In vitro antitumor and antimicrobial activities of $\mathrm{N}$-substituents of maleimide by adamantane and diamantane. Chemotherapy 43: 182-189, 1997.

3. Wang JJ, Chern YT, Liu TY and Chi CW: In vitro and in vivo growth inhibition of cancer cells by adamantylmaleimide derivatives. Anticancer Drug Des 13: 779-796, 1998.

4. Wang JJ, Chern YT, Liu TY and Chi CW: Dimethyladamantylmaleimide induced in vitro and in vivo growth inhibition of human colon cancer Colo205 cells. Anticancer Drugs 13: 533-543, 2002.

5. Wang JJ, Huang KT and Chern YT: Induction of growth inhibition and G1 arrest in human cancer cell lines by relatively low-toxic diamantine derivatives. Anticancer Drugs 15: 277-286, 2004.

6. Wang JJ, Chang YF, Chern YT and Chi CW: Study of the in vitro and in vivo effects of 1,6-Bis[4-(4-amino-3-hydroxyphenoxy) phenyl] diamantane (DPD), a novel cytostatic and differentiation inducing agent, on human colon cancer cells. Br J Cancer 89: 1995-2003, 2003

7. Wang JJ, Chen YC, Chi CW, Huang KT and Chern YT: In vitro and in vivo growth inhibition and $\mathrm{G}_{1}$ arrest in human cancer cell lines by diaminophenyladamantane derivatives. Anticancer Drugs 15: 697-705, 2004.

8. Giovannucci E: Modifiable risk factors for colon cancer. Gastroenterol Clin North Am 31: 925-943, 2002

9. Rougier P, Cutsem EV, Bajetta E, Niederle N, Possinger K, Labianca R, Navarro M, Morant R, Bleiberg H, Wils J, Awad L, Herait $\mathrm{P}$ and Jacques $\mathrm{C}$ : Randomised trial of irinotecan versus fluorouracil by continuous infusion after fluorouracil failure in patients with metastatic colorectal cancer. Lancet 352: 1407-1412, 1998.

10. Saitz LB, Cox JV, Blanke C, Rosen LS, Fehrenbacher L, Moore MJ, Maroun JA, Ackland SP, Locker PK, Pirotta N, Elfring GL and Miller LL: Irinotecan plus fluorouracil and leucovorin for metastatic colorectal cancer. Irinotecan Study Group. N Engl J Med 343: 905-914, 2000.

11. Hecht JR: Gastrointestinal toxicity of irinotecan. Oncology 12: 72-78, 1998.

12. Sherr CJ: $\mathrm{G}_{1}$ phase progression: cycling on cue. Cell 79: 551-555, 1994.

13. Hunter T and Pines J: Cyclins, Cancer II. Cyclin D and CDK inhibitors come of age. Cell 79: 573-582, 1994.

14. Massague J: G1 cell-cycle control and cancer. Nature 432: 298-306, 2004

15. Yamamoto H, Soh JW, Shirin H, Xing WQ, Lim JTE, Yao Y, Slosberg E, Tomita N, Schieren I and Weinstein IB: Comparative effects of overexpression of p27kip1 and p21cip1/waf1 on growth and differentiation in human colon carcinoma cells. Oncogene 18: 103-115, 1999.
16. Lees E: Cyclin dependent kinase regulation. Curr Opin Cell Biol 7: 773-780, 1995.

17. Sherr CJ: Cancer cell cycles. Science 274: 1672-1677, 1996.

18. Hussussian CJ, Struewing JP, Goldstein AM, Higgins PAT, Ally DS, Sheahan MD, Clark WH Jr, Tuker MA and Dracopoli NC: Germline p16 mutations in familial melanoma. Nat Genet 8: 15-21, 1993.

19. Nobori T, Miura K, Wu DJ, Lois A, Takabayashi K and Carson DA: Deletions of the cyclin-dependent kinase-4 inhibitor gene in multiple human cancers. Nature 368: 753-756, 1994.

20. Cohen E, Ophir I and Shaul YB: Induced differentiation in HT29, a human colon adenocarcinoma cell line. J Cell Sci 11: 2657-2666, 1999.

21. Fantini J, Rognoni JB, Verrier B, Lehmann M, Roccabianca M, Meauchamp J and Marvaldi J: Suramin-treated HT29-D4 cells grown in the presence of glucose in permeable culture chambers form electrically active epithelial monolayers. A comparative study with HT29-D4 cells grown in the absence of glucose. Eur J Cell Biol 51: 110-119, 1990.

22. Brattain MG, Levin A, Chakrabarty S, Yeoman I, Willson J and Long B: Heterogeneity of human colon carcinoma. Cancer Metastasis Rev 3: 177-191, 1984.

23. Drewinko B, Romsdahl MM, Yang LY, Ahearn MJ and Trujillo JM: Establishment of a human carcinoembryonic antigen-producing colon adenocarcinoma cell line. Cancer Res 36: 467-475, 1976.

24. Huang S and Chakrabarty S: Regulation of fibronectin and laminin receptor expression, fibronectin and laminin secretion in human colon cancer cells by transforming growth factor $B$. Int J Cancer 57: 742-746, 1994.

25. Dahl SC and Grabel LB: Integrin phosphorylation is modulated during the differentiation of F-9 teratocarcinoma stem cells. J Cell Biol 108: 183-190, 1989.

26. Lotan R, Lotan D and Carralero DM: Modulation of galactoside-binding lectins in tumor cells by differentiation inducing agents. Cancer Res 48: 115-122, 1989.

27. Vermeulen SJ, Bruyneel EA, Roy FM van, Mareel MM and Brackel ME: Activation of the E-cadherin/catenin complex in human MCF-7 breast cancer cells. Br J Cancer 72: 1447-1453, 1995

28. Hynes RO and Lander AD: Contact and adhesive specificities in the associations, migration and targeting of cells and axons. Cell 68: 303-322, 1992.

29. Liotta LA, Steeg PS and Stetler-Stevenson WG: Cancer matastasis and angiogenesis: an imbalance of positive and negative regulation. Cell 64: 327-336, 1991

30. Wijnhoven BPL, Dinjens WNM and Pignatelli M: E-cadherincatenin cell-cell adhesion complex and human cancer. Br J Surg 87: 992-1005, 2000

31. St Croix B, Sheehan C, Rak JW, Florenes VA, Slingerland JM and Kerbel RS: E-cadherin-dependent growth suppression is mediated by the cyclin-dependent kinase inhibitor p27 (KIP1). J Cell Biol 142: 557-571, 1998.

32. Levenberg S, Yarden A, Kam Z and Geiger B: p27 is involved in $\mathrm{N}$-cadherin-mediated contact inhibition of cell growth and S-phase entry. Oncogene 18: 869-876, 1999.

33. Nakagawa K, Sogo S, Hioki K, Tokunaga R and Taketani S Acquisition of cell adhesion and induction of focal adhesion kinase of human colon cancer Colo 201 cells by retinoic acidinduced differentiation. Differentiation 62: 249-257, 1998.

34. Aono S, Nakagawa S, Reynolds AB and Takeichi M: p120ctn acts as inhibitory regulator of cadherin function in colon carcinoma cells. J Cell Biol 145: 551-562, 1999.

35. Ozawa M and Ohkubo T: Tyrosine phosphorylation of p120ctn in $\mathrm{v}$-Src transfected $\mathrm{L}$ cells depends on its association with E-cadherin and reduces adhesion activity. J Cell Sci 114: 503-512, 2001.

36. Workman P, Twentyman P, Balkwill F, Balmain A, Chaplin D, Double J, Embleton J, Newell D, Raymond R, Stables J, Stephens T and Wallace J: United Kingdom Co-ordinating Committee on Cancer Research (UKCCCR) guidelines for the welfare of animals in experimental neoplasia (2nd edition). Br J Cancer 77: 1-10, 1998.

37. Attia MA and Weiss DW: Immunology of spontaneous mammary carcinomas in mice. V. Acquired tumor resistance and enhancement in strain A mice infected with mammary tumor virus. Cancer Res 26: 1787-1800, 1966.

38. Tucker EL and Pignatelli M: Catenins and their associated proteins in colorectal cancer. Histol Histopathol 15: 251-260, 2000 
39. Nagafuchi A and Takeichi M: Cell binding function of E-cadherin is regulated by the cytoplasmic domain. EMBO J 7: 3679-3684, 1988.

40. Aho S, Levansuo L, Montonen O, Kari C, Rodeck U and Uitto J: Specific seguences in p120ctn determine subcellular distribution of its multiple isoforms involved in cellular adhesion of normal and malignant epithelial cells. J Cell Sci 115: 1391-1402, 2002.

41. Kondoh N, Schweinfest CW, Henderson KW and Papas TS: Differential expression of S19 ribosomal protein, lamininbinding protein, and human lymphocyte antigen class I messenger RNAs associated with colon carcinoma progression and differentiation. Cancer Res 52: 791-796, 1992.

42. Laferte S and Loh LC: Characterization of a family of structurally related glycoproteins expressing beta 1-6-branched asparagineslinked oligosaccharides in human colon carcinoma cells. Biochem J 283: 193-201, 1992.

43. Stein U, Walther W and Shoemaker RH: Modulation of mdr1 expression by cytokines in human colon carcinoma cells: an approach for reversal of multidrug resistance. Br J Cancer 74: 1384-1391, 1996.

44. Schroder C, Eckert K and Maurer HR: Tributyrin induces growth inhibitory and differentiating effects on HT-29 colon cancer cells in vitro. Int J Oncol 13: 1335-1340, 1998.

45. Tanaka Y, Bush KK, Eguchi T, Ikekawa N, Taguchi T, Kobayashi Y and Higgins PJ: Effect of 1,25-dihydroxyvitamin D3 and its analogs on butyrate-induced differentiation of HT-29 human colonic carcinoma cells and on the reversal of the differentiated phenotype. Arch Biochem Biophys 276: 415-423, 1990.

46. Reynolds S, Rajagopal S and Chakrabarty S: Differentiationinducing effect of retinoic acid, difluoromethylornithine, sodium butyrate and sodium suramine in human colon cancer cells, Cancer Lett 134: 53-60, 1998

47. Wang Y, Cheong D, Chan S and Hooi SC: Heparin/Heparan sulfate interacting protein gene expression is up-regulated in human colorectal carcinoma and correlated with differentiation status and metastasis. Cancer Res 59: 2989-2994, 1999.
48. Velcich A, Palumbo L, Jarry A, Laboisse C, Racevskis J and Augenlicht L: Patterns of expression of lineage-specific markers during the in vitro-induced differentiation of HT-29 colon carcinoma cells. Cell Growth Differ 6: 749-757, 1995.

49. Ohannesian D, Lotan D and Lotan R: Concomitant increases in galectin-1 and its glycoconjugate ligands (carcinoembryonic antigen, lamp-1 and lamp-2) in cultured human colon carcinoma cells by sodium butyrate, Cancer Res 54: 5992-6000, 1994.

50. Niles R, Wilhelm S, Thomas P and Zamcheck N: The effects of sodium butyrate and retinoic acid on cell growth and CEA production in a series of human colorectal tumor cell lines representing different states of differentiation. Cancer Invest 6: $39-45,1988$

51. Ophir I, Cohen E and Ben-Shaul Y: Apical polarity in human colon carcinoma cell lines. Tissue Cell 27: 659-666, 1995.

52. Bates S and Vousden KH: p53 in signaling checkpoint arrest and apoptosis. Curr Opin Genet Dev 6: 1-7, 1996.

53. Waldman T, Kinzleer KW and Vogelstein B: p21 is necessary for the p53-mediated G1 arrest in human cancer cell. Cancer Res 55: 5187-5190, 1995.

54. Fero ML, Rivkin M, Tasch M, Porter P, Carow CE, Firpo E, Polyak K, Tsai LH, Broudy V, Perlmutter RM, Kaushansky K and Robert JM: A syndrome of multiorgan hyperplasia with features of gigantism, tumorigenesis and female sterility in p27/kip1-deficient mice. Cell 85: 733-744, 1996.

55. Pignatelli M, Liu D, Nasin MN, Stamp VH, Hirano S and Takeichi M: Morphoregulator activities of E-cadherin and beta-1 integrins in colorectal tumor cells. Br J Cancer 66: 629-634, 1992.

56. Mann B, Gelos M, Siedow A, Hanski ML, Gratchev A, Ilyas M, Bodmer WF, Moyer MP, Riecken EO, Buhr HJ and Hanski C: Target genes of beta-catenin-T cell-factor/lymphoid-enhancerfactor signaling in human colorectal carcinomas. Proc Natl Acad Sci USA 96: 1603-1608, 1999.

57. Tetsu $\mathrm{O}$ and McCormick F: Beta-catenin regulates expression of cyclin D1 in colon carcinoma cells. Nature 398: 422-426, 1999.

58. Mo $Y Y$ and Reynolds $A B$ : Identification of murine $p 120^{\text {cas }}$ isoforms and heterogeneous expression of p120cas isoforms in human tumor cell lines. Cancer Res 56: 2633-2640, 1996. 